\title{
EL VALOR MEDIÁTICO DE LA VIOLENCIA
}

\author{
THE MEDIA VALUE VIOLENCE
}

\section{AUTOR/ES}

Marta Redondo García: Profesora de la Facultad de Filosofía y Letras. Licenciatura de Periodismo. Universidad de Valladolid. Valladolid (España)

marta.redondo@hmca.uva.es

\section{RESUMEN}

En el sistema actual de medios, acontecimientos de muy variada índole funcionan como insumos en la producción de noticias y se posibilita la competencia entre ellos en la jerarquía informativa. Aquellos hechos que sean capaces de interesar, atraer, subyugar a un mayor número de personas, suben puestos en el escalafón, dado que su presencia posibilita una mejor recepción del producto periodístico. La comunicación aborda cómo, dentro de esta lógica, la violencia se encumbra como valor noticia apetecido, dado el inevitable impacto que su aparición genera. Este privilegio conduce a una "sobrerrepresentación" de la violencia en los medios no equiparable a la violencia que la sociedad soporta en la realidad.

Puesto que la violencia es considerada como un valor noticioso destacado y deseable, en ocasiones, el sensacionalismo contribuye a exagerar e incluso falsificar su presencia con el fin de intensificar el gancho informativo. Si el conflicto y la violencia no existen o aparecen desleídos, pueden llegar a ser forzados para mantener a la audiencia en alerta. La comunicación aporta ejemplos de cómo los medios extreman la realidad tensándola hacia sus manifestaciones más violentas y no sólo en las informaciones a priori más proclives a seguir ese proceso como los sucesos sino también en la actualidad política o el deporte.

Reconociendo la naturaleza inherentemente humana de la violencia, la comunicación constata la esquizofrenia de la sociedad actual que por un lado condena la violencia formalmente, a través del derecho y la moral, y por otro vive, a través de los medios, inundada de hechos e imágenes violentas, favoreciéndolos en su sistema informativo.

\section{PALABRAS CLAVE}

Valores noticia - Violencia - Sensacionalismo - Espectáculo informativo. 
In the current system of media, events of a varied nature work as inputs in the production of news. Those facts that can attract a major number of consumers, raise places in the hierarchy, provided that its presence makes possible a better receipt of the journalistic product. The communication approaches how, within this logic, violence is considered as a desired news value. This privilege leads to an "hyper-representation" of violence in media, not comparable to the violence that society supports in reality.

Since violence is considered to be a desirable news value, sometimes, sensationalism helps to exaggerate its presence in order to intensify the informative hook.

Communication contributes some examples of how media tighten reality towards its more violent manifestations and not only in the information more inclined to this process as accident and crime reports but also in policy or sport.

Admitted the inherently human nature of the violence, the communication states the schizophrenia of the current society: on the one hand condemns violence formally (in law and morality), and on the other lives flooded with facts and violent images, favoring them in its informative system.

\section{KEY WORDS}

Latin vote - News values - Violence - Sensationalism - Infotainment

ÍNDICE

^ 1. EL VALOR MEDIÁTICO DE LA VIOLENCIA

2. BIBLIOGRAFÍA

\section{EL VALOR MEDIÁTICO DE LA VIOLENCIA}

El nacimiento de la prensa de masas a mediados del XIX introdujo cambios en el diseño de los diarios, en el lenguaje que empleaban, en el tratamiento de las noticias pero sin duda el cambio más sustancial afectó a los criterios de noticiabilidad.

El periodismo entendido como un negocio, regido por tanto por la lógica de la comercialidad, ensanchaba el sector del público al que se dirigía y con él ampliaba el concepto de noticia; de forma que ya no era exclusivamente aquello que afectaba a los intereses de las clases pudientes: básicamente economía y política, sino también las historias que la realidad deparaba y que resultaban susceptibles de convertirse en fuente de comentarios y, por ende, en producto atractivo para un gran volumen de personas. 
El periodismo popular contribuyó de este modo a incluir en los diarios, temáticas impensables hasta ese momento: el deporte, la crónica social de las familias acaudaladas, los relatos de interés humano, las curiosidades, pero también, y en lugar destacado, los sucesos y tragedias. Se abrió así la barrera que separaba los asuntos que se entendían de legítimo interés público de aquellos que no lo tenían, y los sucesos adquirieron carta de naturaleza como temas de interés periodístico.

Desde entonces, hechos de muy variada índole funcionan como insumos del sistema de noticias para su posterior jerarquización y elaboración. Numerosos estudios sobre producción periodística han analizado las cualidades que ha de tener un acontecimiento para captar el interés de los medios. Desde la clasificación clásica de Carl Warren (1975) hasta las más recientes de Mauro Wolf (1987) o Wolfgag Donsbach (1995), diversos autores han intentado llegar a la esencia de la noticiabilidad (newsworthiness), a la serie de criterios que ha de cumplir un hecho para convertirse en noticia. Y en muchas ocasiones se ha interpretado que en esa elección juega un papel relevante la dialéctica existente entre la oferta y la demanda de contenidos. Como señala Wolf (1987, p. 115) en el proceso de selección en que están inmersos los gatekeepers de los medios se produce un "diálogo continuo entre producción y consumo".

Como sector económico que es, la comunicación se gobierna por parámetros comerciales y los medios de comunicación, al igual que el resto de empresas, están sometidos a los dictados de una industria en competencia y gobernada por la tensión entre la oferta y la demanda. En ese entorno, los contenidos que ofrecen se convierten en un servicio más que se rige, en buena medida, por la ley de la rentabilidad. Esta circunstancia contextual afecta inevitablemente a la forma en que los medios diseñan su oferta. En esa lógica se comprende que se favorezcan aquellas informaciones que puedan tener una mejor recepción por parte del público, al tiempo que toda demanda detectada sea satisfecha. Dado que el sistema, para su mero mantenimiento ha de resultar rentable, aquella información capaz de atraer, subyugar y entretener a un mayor número de personas, subirá puestos en el escalafón por sus valores noticiosos, puesto que su presencia posibilita una mejor recepción del producto periodístico. Como señala Sánchez Noriega (1997: 68) la "presunción de comercialidad" de un acontecimiento es un valor noticia que influye en la configuración de los contenidos de los medios de comunicación. De Fleur y Ball-Rokeach (1982: 185) han dado las claves de esta ecuación que relaciona las necesidades de las empresas de comunicación y los gustos del público, y que es dominante en nuestros días: "Puesto que el objetivo más esencial del sistema de medios es el lucro económico, el contenido de sexo y violencia, o cualquiera otro que suscite la atención y la mantenga, pasa a ser funcional, en el sentido de que, aunque sea de bajo gusto, lleva una cifra máxima en los volúmenes de público expuesto ante la publicidad comercial".

Esta lógica, presente en todo producto con aspiración a resultar masivo, supone un cambio sobre las funciones que la teoría de la responsabilidad social de la prensa adjudicaba a la información. No serán asuntos periodísticos sólo aquellos que resulten 
más útiles para el progreso social y la buena marcha de la democracia sino que esos asuntos rivalizarán, en la arena de los medios, con aquellos que sean más impactantes y/o que sirvan mejor al entretenimiento. Por tanto, la justificación del periodismo no será estrictamente prestar un servicio público sino también servir a la distracción de lo cotidiano y proporcionar temas de conversación.

Dentro de este planteamiento, la violencia se encumbra como valor noticia apetecido, dado el inevitable impacto que su aparición genera y la seducción que ejerce. Según señala Rodríguez Borges (2007): “Impelidos por el objetivo de maximizar audiencias y beneficios, los medios descubrieron bien pronto que los relatos sobre sucesos, crímenes, catástrofes y otras desgracias resultaban especialmente eficaces para captar y retener la atención de la opinión pública".

En efecto, como se ha estudiado ampliamente, la violencia posee una gran capacidad de atracción sobre las personas, "fascinación" según Garrido Lora (2002: 131147). Satisface su necesidad de excitación, de experimentar emociones fuertes, apela al morbo de encontrarse cerca del peligro pero a salvo, un fenómeno paradójico que, como describe Penalva (2005: 398), mezcla angustia y placer, y roza el masoquismo. Además posibilita ejercitar la compasión por aquellos que la sufren y al tiempo compararse con ellos para íntima satisfacción por sentirse fuera de peligro.

Esta capacidad para impresionar y conmover, impactar y aliviar al tiempo, hace que los acontecimientos que cuentan con el componente de la violencia tengan un puesto preponderante en los medios; preponderante y creciente. Iñigo Marauri (2008) analizó en su tesis doctoral la evolución del tratamiento periodístico de los sucesos en la prensa diaria de información general de España desde 1977 hasta 2001, tomando como objeto de estudio los principales diarios de referencia: El País, ABC, El Mundo, Diario 16, El Periódico de Catalunya, La Vanguardia y El Correo. Entre las conclusiones de su investigación, sobresale la constatación de que la relevancia de los sucesos, lejos de disminuir, creció en ese periodo. Además, según comprobó, estas informaciones ocupan un lugar cada vez más privilegiado en el diseño de las páginas, siendo destacadas en la primera de la sección o la portada del diario, con un incremento también en el número y dimensión de las fotografías que acompañan a los artículos de sucesos. La tesis concluye asimismo, que el tratamiento de esas informaciones habría evolucionado hacia una mayor aparición de tintes melodramáticos, descripciones escabrosas y relatos que potencian el valor espectacular de la tragedia. Una tendencia que también ha indicado Carmen Herrero (2003: 9): “En muchas ocasiones, el periodismo de sucesos se ve tentado a abandonar el rigor informativo a favor de un relato afectivo-emotivo en el que predomina la simplificación y el sentimentalismo, en perjuicio de una explicación histórica y esencial del acontecimiento".

Descubierto el valor noticioso de la violencia, y siguiendo el planteamiento de De Fleur y Ball Rockeach, podemos deducir que existe una violencia funcional que los medios emplean para impactar a sus receptores y atraerlos. En efecto, parecería que la 
mesura no vende, que, como afirma John Hartley (1982: 83), "El pan y la mantequilla de las noticias son los conflictos, la violencia, la rivalidad y la discrepancia". La noticia negativa es más llamativa y subyugante, por tanto la que adquiere más valor, de forma que incluso se asocia al olfato periodístico, la capacidad del informador para encontrar el antagonismo, lo anómalo, la violencia física o psicológica que existe en las relaciones políticas, económicas, deportivas o sentimentales.

Si la violencia es considerada como un valor noticioso destacado y deseable, la lógica nos lleva a concluir que, en ocasiones, el sensacionalismo contribuye a exagerar e incluso falsificar su presencia con el fin de intensificar el gancho informativo. Hallado el valor noticioso de la violencia, el periodista que siga el paradigma sensacionalista, estará tentado de encontrar ese ingrediente en la realidad como criterio selectivo, y a destacarlo cuando aparezca, por su utilidad como señuelo.

Pongamos un ejemplo que ilustra claramente este forzamiento de la realidad hacia sus extremos más agresivos. El hecho origen de la noticia tuvo lugar durante la celebración de la Eurocopa de fútbol de 2004. Dos días antes del partido de octavos de final entre las selecciones de Portugal y España, que supondría la eliminación del equipo español, un periodista de una cadena de radio, telefonea al seleccionador nacional de Portugal Luis Felipe Scolari para pedirle su opinión sobre el partido. Scolari se disculpa por no poder atenderle porque entiende que sus declaraciones pueden ser malinterpretadas y generar una polémica que no desea. Recogida de forma textual, su respuesta, en un castellano tosco fue la siguiente: "Discúlpeme, pero yo no hablo ahora con los españoles. Es una guerra y en las guerras tengo que matar y no morir. Ustedes son españoles y yo portugués. Tenemos un partido. Cualquier cosa que yo diga será diferente. Es mejor que no nos hablemos". Enseguida la disculpa por no poder dar noticias nuevas se convierte, gracias al afán sensacionalista del periodista, en la noticia deportiva de la jornada. Al día siguiente El Mundo Deportivo titula: "Esto es la guerra". Debajo, el siguiente subtítulo para calentar a la afición: "El seleccionador de Portugal agota la baza del sentimiento patriótico ante el decisivo duelo de mañana frente a España. 'Se trata de matar, no de morir', clama el brasileño".

El diario transformó así una evasiva en una declaración de guerra; la ausencia de noticia se convirtió en una provocación gracias al tratamiento deformado de unas explicaciones que intentaban evitar a toda costa la confrontación.

No sólo el deporte, también la comunicación política hace hincapié en el enfrentamiento y la hostilidad. La violencia verbal se considera ya parte cardinal del juego retórico en la vida pública. Paradójicamente, una víctima de la violencia Tomás y Valiente denunciaba en 1995 que los medios contribuyesen a transformar la política en un espectáculo agresivo y no en acción de gobierno: "Las entrevistas buscan, con frecuencia por ambas partes (se refiere a políticos y periodistas), la frase mordaz y la contestación sarcástica a lo que otro ha dicho en otra entrevista. (...). Sólo parece que cuenten, pues eso es lo que con frecuencia, cuando no de forma exclusiva, se transmite, 
los minutos de enfrentamiento entre líderes, las frases hirientes, la esgrima entre ingeniosa y mordaz que en ocasiones se convierte en dura violencia verbal".

De esta forma las fuentes, conocedoras de aquellos elementos que los medios prefieren, se mimetizan con las exigencias de éstos con el fin de asegurarse la atención periodística. La política influida por los medios y afectada por éstos queda en manos del efectismo.

Este fenómeno de potenciación del conflicto por parte de la prensa hasta aquí expuesto se ve intensificado además, por los medios audiovisuales y principalmente por la televisión cuyo encumbramiento como medio dominante ha supuesto un nuevo ajuste del concepto de noticia. La televisión, erigiéndose como el medio más influyente, obligó, como señalan Gómez Mompart y Marín Otto (1999: 251), a un nuevo proceso de "redefinición del discurso periodístico", proceso que se inicia en la década de los 90 del pasado siglo: "la televisión relevará a la prensa en cuanto a ser el medio informativo no solamente de mayor audiencia e influencia, aspectos estos que ya venían de lejos, sino que se convertirá en dominante y de referencia obligada para los demás medios, o sea, el que marca las pautas, muchos temas, los enfoques, los debates, los escenarios, los personajes... y, algo que es crucial en la cultura periodística, el estilo de qué es noticia, es decir, lo excepcional para los profesionales y cómo ello debe presentarse".

Con la hegemonía de la televisión, la espectacularidad de las imágenes que depara un acontecimiento se añade a la lista de características que se priorizan en un hecho destinado a convertirse en noticia. El impacto de la escena grabada supone un código de idoneidad de cara a su incorporación a la agenda de los medios. En significativa continuidad con el criterio de selección temática de la primera prensa sensacionalista, el espectáculo televisivo se decanta por la terna temática que recogía el aforismo "sangre, sexo y escándalo" (blood, sex and scandal) convirtiéndola en la fórmula de éxito en muchos programas de gran audiencia.

De nuevo la violencia resulta privilegiada en esta escala de valores. Basta encender la televisión para comprobar cómo goza de una presencia dominante en la pantalla, en absoluto comparable a la violencia real que la sociedad soporta. Si repasamos el listado de series más vistas comprobaremos cómo es un elemento constitutivo, cuando no el eje temático, de los argumentos en muchas de ellas.

Y si la violencia resulta visualmente deseable en los productos de ficción, también en aquellos otros cuyo cometido es dar cuenta de la realidad: los informativos, donde cumple la misma funcionalidad. Los noticieros televisivos que son, para una mayoría, el recurso principal, cuando no único, para el conocimiento de los acontecimientos relevantes para la sociedad, en ocasiones se convierten en una galería de desastres e imágenes agresivas. De esta preferencia de las noticias televisivas por las acciones de violencia ha hablado Giovanni Sartori (1998: 95): “La televisión llega siempre con rapidez al lugar donde hay agitación, alguien protesta, se manifiesta, ocupa edificios, bloquea 
calles y ferrocarriles y, en suma, ataca algo o alguien. Se podría pensar que esto sucede porque un ataque puede resultar un espectáculo, y la televisión es espectáculo. En parte esto debes ser así. Pero el mundo real no es espectáculo y el que lo convierte en eso deforma los problemas y nos desinforma sobre la realidad".

Esta impresión encuentra su confirmación en un estudio realizado conjuntamente por las universidades de Navarra, Complutense y Pompeu Fabra entre julio de 2005 y junio de 2006 que revelaba que en ese periodo las noticias sobre desastres y accidentes incrementaron su presencia. Esta radiografía de los telediarios de las principales cadenas destacaba la especial presencia de la violencia en sus distintas manifestaciones: terrorismo, sucesos, catástrofes en las cadenas privadas Antena 3 y Telecinco, sólo superada por la información deportiva a la que las cadenas destinaban una cuarta parte de sus contenidos.

Ciertamente, en ocasiones la espectacularidad de la violencia parece ser el único valor noticia de determinadas informaciones televisivas. De nuevo aportamos un ejemplo. En 2004 tuvo lugar un motín en la prisión brasileña de Rondonia. Todas las televisiones españolas ofrecieron imágenes de ese levantamiento a pesar de que se había producido en un lugar lejano y por cuestiones particulares del centro penitenciario. El motivo fue, sin duda, la monstruosidad de las imágenes que grabaron los cámaras: los cuerpos de dos presos decapitados tras un ajuste de cuentas entre reclusos. De este modo, una noticia, de la que no nos habríamos enterado o que, como máximo, hubiera sido un breve, conquistó, gracias al pasaporte de la atrocidad, un lugar relevante en todas las pantallas. Seguramente si las imágenes del motín hubiesen sido menos morbosas, más anodinas, jamás hubiéramos sabido lo que ocurría en Rondonia. Como irónicamente señalaba el escritor Javier Marías (2004: 122), los informativos no deberían haber introducido la noticia señalando: "Se amotinan presos de una cárcel brasileña y matan a varios reclusos", sino: “Tenemos imágenes confusas de la decapitación de dos hombres, y nítidas de sus cuerpos descabezados y de sus cabezas sin cuerpo. Véanlas, que se las ofrecemos. Son gentileza de unos presos de Brasil, amotinados".

Evidentemente la violencia es un ingrediente que está muy presente en la sociedad. Puede incluso, como algunos afirman, que sea un comportamiento inherente al ser humano y que estemos condenados a padecerla de forma inexorable. Dada su existencia, los medios de comunicación han de dar cuenta de ella puesto que resultaría hipócrita y manipulador ocultarla. Pero, sin duda, el lugar de preeminencia que ocupa en la jerarquía mediática conduce a su "sobrerrepresentación": una presencia constante, hiperbolizada, a menudo descontextualizada, que contribuye a ofrecer una imagen tergiversada y tremendista del entorno.

No es nuestro objetivo aquí, aunque sería sin duda la fórmula más pragmática de abordar el problema, tratar las consecuencias que esa sobreexposición a la violencia tiene sobre los consumidores de medios. Numerosos estudios han apuntado caminos diversos e interesantes: la relación entre violencia televisiva y violencia real, la pérdida de 
sensibilidad ante las acciones agresivas, el efecto de generar miedos e inseguridades que pesan en el ánimo colectivo (el síndrome del mundo mezquino -mean world- acuñado por Gerbner) con implicaciones sobre el control social, e, incluso, la violencia como pasaporte para la notoriedad en sectores sociales especialmente influenciables como los jóvenes y adolescentes.

Aquí nos limitamos simplemente a constatar la paradoja en la que vivimos. La sociedad adquiere noción de sí misma a través de los medios de comunicación puesto que ya Walter Lippman reconoció en ellos su capacidad de generar un "pseudoentorno", una conciencia colectiva. Pues bien, esa conciencia creada mediáticamente insiste en la percepción de habitar un mundo necesariamente violento, incluso subyugantemente violento puesto que en muchas ocasiones la violencia forma parte del espectáculo y se impregna de las connotaciones positivas de éste. A su vez, esa imagen, deformada por unos medios que consideran la violencia como un valor noticia privilegiado, se convierte “en punto de referencia para la opinión pública y la clase política" (Barata 1999: 3)

Ahí radica la contradicción: la evolución de la civilización parece dirigirse teóricamente por el camino del control de la violencia, de forma que una sociedad más avanzada pasaría por ser una sociedad más pacífica. Sin embargo, la imagen que la sociedad ofrece de sí misma a través de los medios es la de una comunidad violenta y en permanente conflicto. Una tensión que conduce a la esquizofrenia de condenar la violencia formalmente (a través de la ética y el derecho) pero vivir rodeados de representaciones de ella, incapaces de escapar a la sugestión que nos causa.

\section{BIBLIOGRAFÍA}

- COLOMBO, Furio: Últimas noticias sobre el periodismo. Manual de periodismo internacional. Barcelona, 1997. Anagrama.

- De FLEUR, Melvin L. y BALL-ROKEACH, Sandra J.: Teorías de la comunicación de masas. Barcelona, 1982. Paidós.

- DONSBACH, Wolfgang: Contenidos, comunicación y efectos de la comunicación política. En MÚÑOZ-ALONSO, Alejandro y ROSPIR, Juan Ignacio: Comunicación política. Madrid, 1995. Universitas. Pags. 41-67.

- GARRIDO, Manuel: La fascinación por la violencia televisiva. En: Revista Internacional de Comunicación Audiovisual, Publicidad y Estudios Culturales vol.1, 2002. Pags. 131147. 
- GÓMEZ MOMPART, Josep Luis y MARÍN OTTO, Enric (eds.): Historia del periodismo universal. Madrid, 1999. Síntesis.

- GOMIS, Lorenzo; Teoría del periodismo. Cómo se forma el presente. Barcelona, 1991. Paidós.

- HARTLEY, John: Understanding News. Londres. 1982. Methuen.

- HERRERO, Carmen: Periodismo de sucesos y tribunales. Tratamiento informativo de la violencia social. Sevilla, 2003. Padilla.

- LIPPMAN, Walter: Public Opinion. Nueva York, 1997 (primera edición 1922). Free Press.

- MARAURI, Íñigo: Evolución en el tratamiento de los sucesos en la prensa diaria de información general en España (1977-2000). Tesis doctoral leída el 17/12/2008 en la Universidad del País Vasco. Inédita.

- MARÍAS, Javier: Se empezó mordiendo al perro. El País Semanal, 9 de mayo de 2004.

- PENALVA, Clemente: El tratamiento de la violencia en los medios de comunicación. En: Alternativas. Cuadernos de Trabajo Social, vol. 10, 2002. Pags. 395-412

- RODRÍGUEZ Borges, Rodrigo Fidel: La propagación mediática del miedo. El caso del macroinforme sobre el acoso escolar. En: Espéculo. Revista de estudios literarios, $\mathrm{n}^{\mathrm{O}}$ 37, 2007.

- SÁNCHEZ NORIEGA, José Luis: Crítica de la seducción mediática. Comunicación y cultura de masas en la opulencia informativa. Madrid, 1997. Tecnos.

- SARTORI, Giovanni: Homo videns. La sociedad teledirigida. Madrid, 1998. Taurus.

- TOMÁS Y VALIENTE, Francisco: El clima, El País, 5 de marzo de1995.

- WOLF, Mauro: La investigación de la comunicación de masas. Crítica y perspectivas. Barcelona, 1987. Paidós. 